Erratum

\title{
Increased proteinase expression during tumor progression of cell lines down-modulated for TIMP levels: \\ a new transformation paradigm?
}

Rama Khokha ${ }^{1, *}$, Paul Waterhouse ${ }^{1}$, Peeyush Lala ${ }^{2}$, Mitchell Zimmer ${ }^{1, *}$, and David T. Denhardt ${ }^{1}$

${ }^{1}$ Cancer Research Laboratory, ${ }^{2}$ Department of Anatomy, University of Western Ontario, London, Ontario, N6A 5B7, Canada

In: J Cancer Res Clin Oncol (1991) 117:333-338

Due to an unfortunate misinterpretation the paper by Khokha et al. was printed with a severely distorted title. The correct title and the names of the authors should have appeared as above. 